\title{
BIBLIOGRAFÍA SOBRE EL CONSEJO GENERAL DEL PODER JUDICIAL Y CUESTIONES AFINES
}

CARMEN FERNÁNDEZ-MIRANDA CAMPOAMOR

Profesora Titular de Derecho Constitucional

UNED 
SUMARIO

Manuales. - Monografias. Revistas .- Jurisprudencia ConstituCional. - Legislación Documentación.- Prensa. 
Revista de Derecho Político, núm. 35, 1992, pp. 339-358

\title{
BIBLIOGRAFÍA SOBRE EL CONSEJO GENERAL DEL PODER JUDICIAL Y CUESTIONES AFINES
}

POR

\author{
CARMEN FERNÁNDEZ-MIRANDA CAMPOAMOR
}

Profesora Titular de Derecho Constitucional

UNED

MANUALES

Álvarez Conde, E.: El régimen político español. Madrid, Tecnos, 1983.

Alzaga Villaamil, O.: La Constitución española de 1978. Madrid, Ed. del Foro, 1978.

Cazorla, J.; Ruiz-Rico, J. J., y Bonachela, M.: Derechos, Instituciones y poderes de la Constitución de 1978. (Edit. por los autores), Granada 1983.

Cazorla Prieto, L., y Arnaldo Alcubilla, E.: Temas de Derecho Constitucional y Derecho Administrativo. Madrid, Marcial Pons, 1988.

Esteban, J. de, y LOPEz GUeRRA, L.: El régimen constitucional español, tomo I. Barcelona, Labor, 1980.

Gimeno Sendra, V.: Fundamentos de Derecho Procesal. Madrid, Ed. Civitas, 1981.

Martinez Cuadrado, M.: La Constitución de 1978. Madrid, Ed. Mezquita, 1982.

OtTo, J. de; Punset, R., y BAStida, F. J.: Lecciones de Derecho Constitucional (órganos constitucionales). Oviedo, Guiastur, 1980. 
Peces-Barba Martínez, G.: La Constitución española. Un estudio de Derecho y Política. Valencia, Fernando Torres, 1981.

SÁNCHEZ AGESTA, L.: Sistema político de la Constitución española de 1978, 6. ${ }^{a}$ ed., Madrid, Edersa, 1991.

TORRes del MORAL, A.: Principios de Derecho Constitucional, tomo II. Madrid, Átomo, 1988.

\section{MONOGRAFIAS}

Álvarez Conde, E.: «Algunas consideraciones sobre la posición constitucional del Poder Judicial», en El Poder Judicial, vol. I. Madrid, I.E.F., 1983.

Agúndez Fernández, A.: Historia de la Justicia en España. Madrid, Editora Nacional, 1974.

-: «Procedimiento electoral para la designación de los miembros del Consejo General del Poder Judicial», en Jornadas de Estudio sobre el Consejo General del Poder Judicial. Madrid, CGPJ y Editora Nacional, 1983.

Alba Navarro, M.: "Las facultades de iniciativa, propuesta e informe en materia legislativa del Consejo General del Poder Judicial», en El Poder Judicial, vol. I. Madrid, I.E.F., 1983.

AlbACAR LOPEZ, J. L.: «La naturaleza del Consejo General del Poder Judicial», en Jornadas de Estudio sobre el Consejo General del Poder Judicial. Madrid, CGPJ y Editora Nacional, 1983.

Almagro Nosete, J.: «Poder Judicial y Tribunal de Garantias en la nueva Constitución", en T. R. FERNANDEZ: Lecturas sobre la Constitución española, tomo I, UNED, 1978.

Andres lbañez, y Movilla Álvarez, C.: El Poder Judicial. Madrid, Tecnos, 1986.

-: Justicia y conflicto. Madrid, Tecnos, 1988.

-: «Note per una possibile riforma democratica della giustizia», en G. De VERGOTTINI (ed.): Una Costituzione democratica per la Spagna. Milano, Franco Angelli, 1978.

Aparicio Pérez, M. A.: "Organización judicial y corporativismo del juez", en Jornadas de Estudio sobre el Consejo General del Poder Judicial. Madrid, CGPJ y Editora Nacional, 1983. 
ATTARD, E.: La Constitución por dentro. Madrid, Argos Vergara, 1983.

AZCARATE, G.: El régimen parlamentario en la práctica. Madrid, Libreria de Fernando $\mathrm{Fe}, 1892$.

BACHOF, O.: Jueces y Constitución. Madrid, Cívitas, 1985.

Bandres Sanchez-Cruzat, J. M.: Poder Judicial y Constitución. Barcelona, Bosch, 1987.

BASTIDA, F. J.: Jueces y Franquismo. El pensamiento político del T.S. en la Dictadura. Barcelona, Ariel, 1986.

BONET NAVARRO, A.: Escritos sobre la jurisdicción y su actividad. Zaragoza, Instituto Fernando el Católico (CSIC), 1981.

BURON BARBA, L. A.: «El Consejo General del Poder Judicial y la independencia de la función jurisdiccional», en Jornadas de Estudio sobre el Consejo General del Poder Judicial. Madrid, CGPJ y Editora Nacional, 1983.

CANo Bueso, J.: La política judicial del régimen de Franco (1936-1945). Madrid, Ministerio de Justicia, 1985.

Carretero Pérez, A.: "La potestad reglamentaria y la iniciativa legislativa del Consejo General del Poder Judicial», en Jornadas de Estudio sobre el Consejo General del Poder Judicial. Madrid, CGPJ y Editora Nacional, 1983.

-: «El modelo de Poder Judicial en la Constitución», en El Poder Judicial, vol. I. Madrid, I.E.F., 1983.

-: «Incidencia actual de la Constitución sobre el Poder Judicial», en Homenaje a Carlos Ruiz del Castillo. Madrid, I.E.A.L., 1985.

Castedo Álvarez, F.: «La potestad reglamentaria del Consejo General del Poder Judicial», en El Poder Judicial, vol. I. Madrid, I.E.F., 1983.

Cavero Lataillade, I.: "La estructura organizativa del Poder Judicial. Comentario al art. 122 de la Constitución", en O. ALzAGA: Comentario a las Leyes Politicas, tomo IX. Madrid, Edersa, 1987.

-: El desarrollo constitucional y legislativo y la reorganización de la justicia. Madrid, Ministerio de Justicia, 1980.

CĺrCULO de Estudios JuRIDicos: La independencia judicial. Madrid 1970.

Crespo MARquez, J. M.: «El principio de separación de poderes y su vigencia actual. El Poder Judicial y la función jurisdiccional», en I Jornadas de Derecho Judicial. Madrid, Tribunal Supremo, 1983. 
Dean Guelbenzu, N.: «El contenido de las actas de inspección» (Comunicación), en Jornadas de Estudio sobre el Consejo General del Poder Judicial. Madrid, CGPJ y Editora Nacional, 1983.

Delgado Barrio, J.: «Régimen jurídico de los actos del Consejo: Su impugnación» (Comunicación), en Jornadas de Estudio sobre el Consejo General del Poder Judicial. Madrid, CGPJ y Editora Nacional, 1983.

Diaz VAlCÁRCEL, L. M.: «El Consejo General del Poder Judicial y las Comunidades Autónomas", en Jornadas de Estudio sobre el Consejo General del Poder Judicial. Madrid, CGPJ y Editora Nacional, 1983.

DIez-PICAZO, L. M. ${ }^{a}$ : Régimen constitucional del Poder Judicial. Madrid, Cívitas, 1991.

DiETER, S.: La independencia del juez (prólogo de M. A. Aparicio). Barcelona, Ariel, 1985.

Dominguez MARTín, S.: Estudio sobre la Ley Orgánica del Poder Judicial. Madrid, Presidencia de Gobierno, 1982.

-: «Perspectivas y realidades del gobierno del Poder Judicial creado por la Constitución", en El Poder Judicial, vol. II. Madrid, I.E.F., 1983.

FAirén Guillén, V.: Comentarios a la Ley Orgánica del Poder Judicial de 1 de julio de 1985. Madrid, Edersa, 1986.

FERNÁNDEZ FARRERES, G.: «Las asociaciones profesionales de jueces y magistrados», en El Poder Judicial. Madrid, I.E.F., 1983.

Fernandez Ordoñez, F.: «La independencia del Poder Judicial», en La justicia en la década de los 80. Madrid, Ministerio de Justicia, 1981.

Fernández-Carnicero González, C. J.: «Relaciones entre el Poder Judicial y las Cortes Generales», en El Poder Judicial, vol. II. Madrid, I.E.F., 1983.

Fernández-Viagas Bartolomé, P.: «El Consejo General del Poder Judicial y los conflictos constitucionales", en Jornadas de Estudio sobre el Consejo General del Poder Judicial. Madrid, CGPJ y Editora Nacional, 1983.

-: "Los conflictos constitucionales y el Poder Judicial», en A. LOPEZ PINA (ed.): La Constitución de la Monarquia parlamentaria. Madrid, Fondo de Cultura Económica, 1983.

Fraile Clivilles, M.: "Las Cortes Generales y el Poder Judicial», en |/ Jornadas de Derecho Parlamentario. Madrid, Cortes Generales, 1986.

Garcia Canales, M.: «Reflexiones sobre el Poder Judicial en la Constitución 
española de 1978", en Derecho y Proceso. Estudios Jurídicos en honor del profesor A. Martínez Bernal. Murcia, Universidad, 1980.

GARCla MACHO, R.: Reserva de ley y potestad reglamentaria. Barcelona, Ariel, 1987.

Garcla RocA, F. J.: El conflicto entre órganos constitucionales. Madrid, Tecnos, 1987.

Garcia-Barban Castañeda, J.: «Composición del Consejo General», en Jornadas de Estudio sobre el Consejo General del Poder Judicial. Madrid, CGPJ y Editora Nacional, 1983.

GonzÁlez Rivas, J. J.: «El Consejo General del Poder Judicial: trascendencia de su creación», en Jornadas de Estudio sobre el Consejo General del Poder Judicial. Madrid, CGPJ y Editora Nacioṇal, 1983.

-: $\quad$ «a independencia judicial: especial consideraçión del artículo 122 de la Constitución española de 1978", en El Poder:Judicial, vol. II. Madrid, I.E.F., 1983.

Gordillo Garcla, M.: «La independencia del Poder Judicial ante el Tribunal Constitucional", en Jornadas de Estudio sobre el Consejo General del Poder Judicial. Madrid, CGPJ y Editora Nacionał, 1983.

Jiménez HernAndez, J. J.: «Funciones disciplinarias e inspectoras del Consejo General del Poder Judicial», en Jornadas de Estudio sobre el Consejo General del Poder Judicial. Madrid, CGPJ y Editora Nacional, 1983.

Hernandez MARTín, V.: La independencia del juez y desorganización judicial. Madrid, Cívitas, 1991.

Ledesma BARTRET, F.: «El Poder Judicial en el tránsito de la dictadura a la democracia», en Justicia en la revolución. Memoria del Seminario Jurídico Silvio Mayorga, Managua 1981.

-: $\quad$ «Relaciones entre el Consejo General del Poder Judicial y el Poder Ejecutivo", en Jornadas de Estudio sobre el Consejo General del Poder Judicial. Madrid, CGPJ y Editora Nacional, 1983.

LINDE Paniagua, E.: «El Poder Ejecutivo y la Justicia», en La Justicia en la década de los 80. Madrid, Ministerio de Justicia, 1981.

LORENTE HURTADO, F.: «Potestades inherentes al gobierno del poder judicial: potestad reglamentaria y potestad de gasto", en Jornadas de Estudio sobre el Consejo General del Poder Judicial. Madrid, CGPJ y Editora Nacional, 1983.

MARÍn CASTAN, F.: «Control democrático y legitimación del Poder Judicial», en 
El Poder Judicial en el conjunto de los poderes del Estado y de la sociedad. Madrid, P. J. número especial-XI, CGPJ, 1989.

MARINO BORNEGO, R. de: "Independencia judicial, autonomía y autogobierno", Jornadas de Estudio sobre el Consejo General del Poder Judicial. Madrid, CGPJ y Editora Nacional, 1983.

MARTín PALLín, J. A.: "Control jurisdiccional de los actos del Consejo General», en Jornadas de Estudio sobre el Consejo General del Poder Judicial. Madrid, CGPJ y Editora Nacional, 1983.

Martínez Bernal, A.: «El Poder Judicial», en Derecho y Proceso. Estudios en honor del profesor Martínez Bernal. Murcia, Universidad, 1980.

MATEO LAGE, F.: "Órgano jurisdiccional competente para conocer de la impugnación de los actos y disposiciones del Consejo General del Poder Judicial» (Comunicación), en Jornadas de Estudio sobre el Consejo General del Poder Judicial. Madrid, CGPJ y Editora Nacional, 1983.

MENDizABal AlLende, R.: «Las facultades financieras del Consejo General del Poder Judicial", en Jornadas de Estudio sobre el Consejo General del Poder Judicial. Madrid, CGPJ y Editora Nacional, 1983.

MONTERo AROCA, J.: “Selección de licenciados y formación de jueces", en Jornadas de Estudio sobre el Consejo General del Poder Judicial. Madrid, CGPJ y Editora Nacional, 1983.

-: Independencia y responsabilidad del juez. Madrid, Cívitas, 1990.

-: $\quad$ «Poder Judicial y Administración de Justicia en la Constitución y en la práctica», en E. AlvAREZ CONDE (ed.): 10 años de régimen constitucional. Madrid, Tecnos, 1989.

Mosquero SANCHEz, L.: «La posición del Poder Judicial en la Constitución española de 1978", en A. PREDIERI y E. Garcla de ENTERRIA: La Constitución española de 1978. Madrid, Cívitas, 1980.

Movilla Álvarez, C.: "El autogobierno de la justicia», en Jornadas de Estudio sobre el Consejo General del Poder Judicial. Madrid, CGPJ y Editora Nacional, 1983.

OsSorio y Gallardo, A.: Bases para la reorganización judicial. Madrid, Estudios Sociales, Políticos y Económicos, 1929.

Otto PARDo, J. de: Estudios sobre el Poder Judicial. Madrid, Ministerio de Justicia, 1989.

-: «Poder Judicial», en J. J. GonzÁlez EsPINAR: Diccionario político de la Constitución española. Madrid, Akal, 1984. 
Parada Vazquez, R.: La Administración y los jueces. Caracas, Ed. Jurídica Venezolana, 1988.

Peces-Barba Martínez, G.: «La evolución del Poder Judicial en el constitucionalismo moderno (esquema)", en Jornadas de Estudio sobre el Consejo General del Poder Judicial. Madrid, CGPJ y Editora Nacional, 1983.

Pera Verdaguer, F.: «Régimen jurídico de los actos del Consejo: su impugnación", en Jornadas de Estudio sobre el Consejo General del Poder Judicial. Madrid, CGPJ y Editora Nacional, 1983.

MendizÁbAl AlLende, R. de: "Las facultades financieras del Consejo General del Poder Judicial», en Jornadas de Estudio sobre el Consejo General del Poder Judicial. Madrid, CGPJ y Editora Nacional, 1983.

Prieto Castro, L.; Almagro Nosete, J., y GonzÁlez-Deleito, N.: Tribunales españoles, organización y funcionamiento. Madrid, Tecnos, 1979.

REQUEJo PAGES, L.: Jurisdicción e independencia judicial. Madrid, CEC, 1989.

Rodriguez-Aguilera Prat, C.: El Consejo General del Poder Judicial. BarceIona, Bosch, 1980.

-: El Poder Judicial en la Constitución. Barcelone, Bosch, 1980.

Ruiz PÉrez, J.: «La modernización de los sistemas de selección y perfeccionamiento de los funcionarios judiciales», en Jornadas de Estudio sobre el Consejo General del Poder Judicial. Madrid, CGPJ y Editora Nacional, 1983.

Sainz de Robles Rodriguez, F. C.: «El Consejo General del Poder Judicial como órgano constitucional», en Jornadas de Estudio sobre el Consejo General del Poder Judicial. Madrid, CGPJ y Editora Nacional, 1983.

-: «Poder Judicial y Consejo General del Poder Judicial», en Estudios sobre la Constitución española. Homenaje al profesor Eduardo Garcia de Enterria, tomo IV. Madrid, Cívitas, 1991.

-: "La parlamentarización del Poder Judicial», en VV.AA.: La Constitución española: Lecturas para después de una década. Madrid, Ed. de la Universidad Complutense, 1989.

-: «El Poder Judicial en la Constitución», en El Poder Judicial, vol. I. Madrid, I.E.F., 1983.

Serrano Alberca, J. C.: «Comentarios al Título VI», en Garrido Falla: Comentarios a la Constitución. Madrid, Cívitas, 1980.

Terol Becerra, M. J.: El Consejo General dèl Poder Judicial. Madrid, C.E.C., 1990. 
TOHARIA, J. J.: ¡Pleitos tengas! ... Introducción a la cultura legal española. Madrid, C.I.S., 1987.

-: El juez español: quince años después. Madrid, C.E.C., 1989.

TOMAS VILLARROYA, J.: "Gobierno y Justicia durante la II República", en El Poder Judicial, vol. II. Madrid, I.E.F., 1983.

Vv.AA.: El Poder Judicial, 3 vols. Madrid, I.E.F., 1983.

VV.A.A: Jornadas de Estudio sobre el Consejo General del Poder Judicial. Madrid, CGPJ y Editora Nacional, 1983. 


\section{REVISTAS}

\section{Siglas utilizadas}

\begin{tabular}{|c|c|}
\hline AAd & Actualidad Administrativa \\
\hline $\mathrm{AC}$ & Actualidad Civil \\
\hline AJ & Actualidad Juridica \\
\hline ASPJ & Anuario de Sociología y Psicología Jurídicas \\
\hline BICGPJ & Boletín de Información del Consejo General del Poder Judicial \\
\hline BIMJ & Boletin de Información del Ministerio de Justicia \\
\hline DA & Documentación Administrativa \\
\hline DJ & Documentación Juridica \\
\hline PJ & Poder Judicial \\
\hline RAP & Revista de Administración Pública \\
\hline RCEC & Revista del Centro de Estudios Constitucionales \\
\hline RDJ & Revista de Derecho Judicial \\
\hline RDP & Revista de Derecho Procesal \\
\hline RDPI & Revista de Derecho Procesal Iberoamericano \\
\hline REDA & Revista Española de Derecho Administrativo \\
\hline REDC & Revista Española de Derecho Constitucional \\
\hline REP & Revista de Estudios Políticos \\
\hline RFS & Revista de Fomento Social \\
\hline RGD & Revista General del Derecho \\
\hline RGLJ & Revista General de Legislación y Jurisprudencia \\
\hline RJA & Revista Juridica de Asturias \\
\hline RJC & Revista Jurídica de Cataluña \\
\hline
\end{tabular}


AGÚNDEZ FERnANDEZ, A.: «Garantias Constitucionales de la independencia judicial», $R D P I$, núms. 2-3, 1981.

Alba Navarro, M.: "Las facultades de iniciativa, propuesta e informe en materia legislativa del Consejo General del Poder Judicial», $R A P$, núm. 97 , 1982.

ALBACAR LOPEZ, J. L.: «La organización judicial y el sistema de selección de jueces en la nueva Constitución española”, en L'Ordinamento Giudiziario, Rimini-Magglioli, 1983.

-: «Naturaleza jurídica del Consejo General del Poder Judicial», La Ley, 1982.

Álvarez LINERA, y URIA, C.: "Notas sobre la independencia del Poder Judicial», La Ley, núm. 1, 1982.

ANDRÉS IBÁ̃̃EZ, P.: «Sobre el silencio y disciplina en algunas prácticas del Consejo General del Poder Judicial", en Jueces para la democracia, Información y Debate, núm. 1, 1987.

-: «Notas para una posible reforma democrática de la justicia», en Sistema, núms. 17-18, 1977.

-: “Un nuevo sistema electoral para el Consejo General del Poder Judicial; ¿expansión de la democracia o concentración del poder?», en Consiglio Superiore della Magistratura. Roma, 1985.

-: «Poder Judicial y Estado de Derecho: la experiencia de justicia democrática», Sistema, núms. 38-39, 1980.

Aparicio Pérez, M. A.: "Poder Judicial y división de poderes", Primera Instancia, núm. 7, 1983.

ARozamena SieRra, J.: «Sistema español de función judicial. La carrera judicial», DA, núms. 210-211, 1987.

Auger LIÑAN, C.: «Poder Judicial y Constitución», PJ, núm. 13, 1984.

-: "La formación y selección del personal judicial», en Jornadas sobre el Poder Judicial, DJ, núms. 45-46, 1985.

BASSOLS COMA, M.: «Diversas manifestaciones de la potestad reglamentaria en la Constitución», RAP, núm. 88, 1979.

Carretero Pérez, A.: «Algunos aspectos de la crisis de la justicia», en $A$ Ad, núm. 7, 1988. 
Carretero Perez, A.: «El Poder Judicial desde 1868 a 1898», en $R D J$, núm. 25 , 1966.

-: $\quad$ «Precisiones sobre las facultades de iniciativa del Consejo General del Poder Judicial», RAP, núms. 101-102, 1983.

Carro, J. L., y Gómez Ferrer, R.: «La potestad reglamentaria del Gobierno y la Constitución", en $D A$, núm. 188, 1980.

Consejo General del Poder Judicial: «Informe al Anteproyecto de Ley Orgánica del Poder Judicial», BICGPJ, número extraordinario, marzo 1984.

DALLE, H.: «El autogobierno del Poder Judicial», Jornadas sobre el Poder Judicial, DJ, núms. 45-46, 1985.

Delgado Barrio, J.: «Régimen jurídico de los actos del Consejo General del Poder Judicial: su impugnación», REDA, núm. 32, 1982.

DIETER, S.: «La reforma de la justicia en España», RFS, núm. 96, Madrid 1969.

DOMÍNgUez MARTín, S.: «El autogobierno judicial y la Constitución», BIMJ, núm. 1174, 1979.

FAIRÉn GUILLÉN, V.: “Colofón a un comentario a la Ley Orgánica del Poder Judicial de 1 de julio de 1985”, RDP, núm. 3, 1985.

Fiesta Loza, A.: “La quiebra de la independencia del Poder Judicial», PJ, núm. 14, 1985.

GABALDON LOPEZ, J.: «La responsabilidad disciplinaria de jueces y magistrados", PJ, número especial V-1988.

-: "Control democrático del Poder Judicial», en «El Poder Judicial en el conjunto de los poderes del Estado y de la sociedad», PJ, número especial, XI. Madrid, Consejo General del Poder Judicial, 1989.

Garcla Martínez, M. a A.: «El Consejo General del Poder Judicial y la autonomía del Poder Judicial», Tapia, Publicación para el mundo del Derecho, núm. 55. Madrid 1990.

GaRCía VALDÉS, C.: “La selección y formación de los jueces en España: el Centro de Estudios Judiciales», en PJ, núm. 7, 1987.

Garcla-Pelayo, M.: “El status del Tribunal Constitucional», REDC, núm. 1, 1981.

GARCIA ZARDO, J.: «El contenido del Poder Judicial en la Constitución», BIMJ, núm. 1165, 1979. 
GeRPe Landin, M.: «La composición del Consejo General del Poder Judicial», RCEC, núm. 9, 1991.

Gómez-Reino Carnota, E.: «La justicia ante la Constitución», $R J C$, núm. 4, 1978.

Gonzalez-Cuellas Garcia, A.: «El Poder Judicial en la Constitución», en La Ley, mayo 1989.

Gutiérez Alvy, Y., y Almagro Nosete, J.: «Informe sobre el Anteproyecto de bases para una ley orgánica de la justicia», RDPI, enero-marzo 1969.

JIMÉNEZ DE PARGA, M.: «La independencia del Poder Judicial», Cuadernos para el Diálogo, núm. XVIII, extraordinario sobre justicia y política, diciembre 1969.

LAVILLA Alsina, L.: «Poder Judicial y Constitución», Discurso leído en la apertura de Tribunales (5-9-78). Madrid, Servicio de Publicaciones del Ministerio de Justicia, 1978.

Linde Paniagua, E.: "La composición del Consejo General del Poder Judicial (el apartado 3 del art. 122 de la Constitución en jurisprudencia constitucional», RGLJ, núm. 1, 1985.

LOZANO, B.: «Los conflictos entre la Administración y los Tribunales: perspectiva histórica y nueva configuración», RAP, núm. 118, 1989.

MANZANA LAGUARDA, R.: «Notas de urgencia sobre la vigente Ley Orgánica del Poder Judicial», $R G D$, núm. 492, 1985.

Martín Ruiz, L. F.: "La Ley Orgánica del Consejo General del Poder Judicial y la independencia del juez», RDPI, núms. 2-3, 1980.

MONTERO AROCA, J:: "La función jurisdiccional y el status de jueces y magistrados», en $D J$, núms. 45-46, 1985.

Mosquera SANCHEZ, L.: «Tendencias actuales en Derecho Comparado sobre selección y formación de jueces", RDJ, núm. 6, 1961.

OLIVA, A. de la: "La demolición de la justicia en la futura Constitución de 1978», RDPrJ, núms. 2-3, 1978.

Ollero TASSARA, A.: "Poder Judicial y transición democrática en España», ASPJ (Anuario), 1982.

PASTOR y LOPEZ, M.: «El Consejo General del Poder Judicial», Justicia, número extraordinario, 1981. 
Pedraz Peñalva, E.: «Reflexiones sobre el Poder Judicial y el PLOPJ», La Ley, núm. 1207, 1985.

-: $\quad$ «Reflexiones sobre el Poder Judicial y el Proyecto de Ley Orgánica del Poder Judicial», DJ, núms. 42-44, 1984.

Pérez Morate, J. E.: «El partidismo en el Consejo General del Poder Judicial», en Jueces para la Democracia, núm. 10, septiembre 1990.

Porras Nadales, A.: “Conflictos entre órganos constitucionales del Estado y principio de división de poderes", REP (NE), núm. 52, 1986.

-: «El Consejo General del Poder Judicial según la STC 108/1986 de 29 de julio, sobre la Ley Orgánica del Poder Judicial», REDC, núm. 19, 1987.

Reyes Monterreal, J. M.: «Garantías de autogobierno», PJ, núm. 3, 1982.

Rodríguez-Aguilera Prat, C.: “Acerca del conflicto de atribuciones entre el Consejo General del Poder Judicial y las Cortes Generales en materia electoral’, en $R E D C$, núm. 7, 1987.

Rodriguez-Zapata Pérez, J.: «El Poder Judicial como límite de la potestad de control de las Cortes Generales», REDC, núm. 9, 1983.

Ruiz Pérez, J.S.: «Legitimación democrática del juez», Actualidad Civil, núm. 34, 1986.

RuIZ VADILlO, E.: «La Constitución, la independencia de los jueces y magistrados y el acceso a la carrera judicial», La Ley, núm. 1042, 1984.

SaINZ MORENO, F.: «Inamovilidad judicial», REDA, núm. 11, 1976.

Sainz de Robles Rodríguez, F. C.: "Discurso pronunciado el 2 de diciembre de 1980 en la inauguración del nuevo edificio de los Juzgados de El Ferrol», BIMJ, núm. 1225, 25 de diciembre de 1980.

-: «El Consejo General del Poder Judicial», La Ley, núm. 1, 1980.

-: $\quad$ «Poder Judicial e independencia judicial (Reflexiones sobre un gobierno autónomo para la justicia)", $P J$, núm. 1, 1981.

SAlgado SuAREZ, F.: «EI Poder Judicial en las Constituciones españolas", RJA, núm. $5,1982$.

TOHARIA, J. J.: «Quinto barómetro de opinión del Consejo General del Poder Judicial», en PJ, núm. 19, 1990.

-: "Modernización, autoritarismo y administración de justicia en España», Suplementos de Cuadernos para el Diálogo, núm. 51. Madrid 1974. 
TOMAS Y VALIENTE, F.: «El Poder Judicial en el conjunto de poderes del Estado y de la sociedad", en PJ, núm. XI especial Consejo General del Poder Judicial, 1989.

VACAS Y TENORIO, J.: "Reflexión sobre el órgano de control de los acuerdos del Consejo General del Poder Judicial», La Ley, núm. 2, 1988.

VV.AA.: «Jornadas sobre el Poder Judicial», DJ, núms. 45-46, 1985.

VARELA CASTRO, L.: "Unas jornadas sobre la corrupción", en Jueces para la Democracia, Informe y Debate, núm. 1, 1987.

VILAS BADIA, R.: «El Poder Judicial en el marco de la Constitución española de 1978", AJ, núm. 7, 1981.

XIOL RIOS, J. A.: «El autogobierno del Poder Judicial: la situación en España”, en Jornadas sobre el Poder Judicial, DJ, núms. 45-46, 1985.

Xiol RIos, J. A.; Gonzalez Rivas, J. J., y Rodriguez-Zapata, J.: «El Poder Judicial y su Consejo General en el Estado Social y Democrático de Derecho", PJ (Premios Poder Judicial). Madrid, Consejo General del Poder Judicial, 1990.

\section{JURISPRUDENCIA CONSTITUCIONAL}

- STC 45/1986 de 17 de abril (BOE 29-4-86).

- STC 108/1986 de 29 de julio (BOE 13-8-86).

\section{LEGISLACIÓN}

(desde 1978 a la actualidad)

- Artículo 122 de la Constitución.

- Ley Orgánica 1/1980 de 10 de enero del Consejo General del Poder Judicial.

- Ley Orgánica 6/1985 de 1 de julio del Poder Judicial. 
- Artículos 204-205 y 206 del Reglamento del Congreso de los Diputados ( «De las propuestas de nombramiento y de la designación de personas»: Título XII).

- Artículos 184-185-186 y 187 del Reglamento del Senado ("De las relaciones del Senado con otras instituciones constitucionales": Título (X).

- Acuerdo de 12 de noviembre de 1980, del Consejo General del Poder Judicial por el que se aprueba el Reglamento sobre estructura de los órganos técnicos del Consejo (BOE 1-XII-80).

- Acuerdo de 6 de mayo de 1981, del Consejo General del Poder Judicial por el que se aprueba el Reglamento de personal (BOE 14-V-1981).

- Acuerdo de 27 de mayo de 1981, del Consejo General del Poder Judicial que aprueba el Reglamento de servicios de inspección (BOE 27-VI-1981).

- Acuerdo de 22 de abril de 1986, del Consejo General del Poder Judicial por el que se aprueba el Reglamento de organización y funcionamiento del Consejo General del Poder Judicial (BOE 5-V-1986).

- Acuerdo de 28 de enero de 1987, del Consejo General del Poder Judicial por el que se modifica el artículo 120 , párr. $10^{\circ}$ del anterior Reglamento (BOE 2-II-1987).

\section{DOCUMENTACION}

Boletín de Información del Consejo General del Poder Judicial, Publicación bimensual, Consejo General del Poder Judicial.

Boletin de Información del Ministerio de Justicia, 36 números al año.

Consejo General del Poder Judicial. Compendio estadístico de la labor realizada por los órganos judiciales durante el cuatrienio 1981-1984. Madrid, Consejo General del Poder Judicial, 1985.

Consejo General del Poder Judicial. Memorias sobre el estado y actividades de la justicia que remite a las Cortes Generales y al Gobierno, el Consejo General del Poder Judicial, en 1981-82-83-84, fechas cits.

Consejo General del Poder Judicial. Memoria que el Consejo General del Poder Judicial eleva a las Cortes Generales, en 1988-89-90. Madrid, Consejo General del Poder Judicial, fechas cits.

Consejo General del Poder Judicial. Memoria sobre el estado, funcionamien- 
to y actividades del Poder Judicial y de los Juzgados y Tribunales de Justicia, en 1985-86-87. Madrid, Consejo General del Poder Judicial, fechas cits.

Cortes Generales. Constitución española. Trabajos parlamentarios, 4 vols. Madrid, Servicio de Publicaciones de las Cortes Generales, 1980.

Cortes Generales. Ley Orgánica del Poder Judicial. Ley Orgánica 6/1985 de 1 de julio. Trabajos parlamentarios. Madrid, Servicio de Publicaciones de las Cortes Generales, 1986.

Instituto Nacional de Estadistica. Estadísticas judiciales anuales, Publicación anual, Madrid.

\section{PRENSA}

$A B C$, «Sentencias y Consejos», 30 de julio de 1986. Editorial.

Alvarez Cruz, E.: «La democratización del Poder Judicial», en El Pais, 19-III-1985.

ANDRÉs IbAÑez, P.: “¿Más democracia para la justicia?», El País, 11-V-1985.

Artículos varios en Diario 16, El Sol, El País, El Mundo, $A B C$, El Independiente, dias 23 de octubre a 14 de noviembre de 1990.

BANDREs Molet, J.: "Yo tuve la culpa», El Pais, 31-octubre-1990.

Bernat Freixes, J. M.: "El laberinto del Consejo General del Poder Judicial», El Pais, 17-XI-1990.

Consejo General del Poder Judicial. Nota hecha pública en El Pais, 12 y 13 de mayo de 1981.

CuAdra, B. de la: «Del dicho al hecho", El País, 4-julio-1988.

-: «EI PSOE vota a Auger para presidir el Poder Judicial», El Pais, 20-X-1991.

DIARIO 16, «Montesquieu está grave». Editorial, 23-X-1990.

DIARIO 16, «El pecado original del Consejo General del Poder Judicial». Editorial, 29-septiembre-1991. 
DIARIO 16, «La tragedia de la justicia». Editorial, 14-X-1991.

DoñAte, A.: «Independencia judicial y democracia», El Pais, 25-V-1991.

EL MUNDO, «La tragicomedia del Poder Judicial». Editorial, 3-X-1991.

EL MUNDO, «La forzada indignación del Consejo General del Poder Judicial». Editorial, 24-X-1991.

EL PA/S, «El útimo requerimiento». Editorial, 24-octubre-1985.

El PAIS, "La elección de la cima judicial». Editorial, 1 de agosto de 1986.

EL. PA/S, 19 y 31 de marzo, 9 y 15 de abril y 11 de mayo de 1985.

EL PAIS, «Malos consejos». Editorial, 8-noviembre-1990.

EL PAIS, «Consejo aletargado». Editorial, 26-septiembre-1991.

Esteban, J. de: «Las tribulaciones del Poder Judicial», en El Mundo, 2-X-1991.

GonzAlez Ballesteros, T.: «El Parlamento y los jueces», Diario 16, 22-XI-1990.

GoR, F.: «Hacia otro modelo de colaboración», El País, 13-mayo-1981.

GuerRA, A.: Declaraciones a El País, 23-septiembre-1985.

HeRnÁNDEZ GIL, A.: "Hacia una nueva etapa de la Administración de justicia», en Le Monde Diplomatique, edición especial "La Administración de Justicia en España», 1990.

Manzanares, J. L.: Entrevista en Diario 16, 3-XII-1990.

Oliva SANTOS, A. de la: “¿Qué puede hacer, hoy, el Consejo General del Poder Judicial?», Diario 16, 6-X-1991.

Pradera, J.: «El reparto del botin», El Pais, 11-XI-1990.

Ramirez, P. J.: «La gran burla», El Mundo, 4-XI-1990.

REQUero IBAÑ̃ez, J. L.: "España: hacia el control politico de la justicia", en Le Monde Diplomatique, edición especial sobre «La Administración de Justicia en España», 1990.

REVISTA PODER JUdICIAL, Sección «La Prensa ha dicho».

SALA, P.: Entrevista en El Sol, 17-XI-1990. 
URbano, P.: «El show surrealista del Poder Judicial», en El Mundo, 29-IX-1991.

-: «Presidente Sala, jestán presionando a un juez!», en El Mundo, 21-julio-1991.

La Vanguardia, «La Sentencia del Poder Judicial». Editorial, 31-julio-1986.

YANES, E.: Entrevista en EI Sol, 24-IX-1991.

ZaRzALEJos, J. A.: Entrevista en Diario 16, el 9-XII-1990.

Madrid, diciembre 1991 